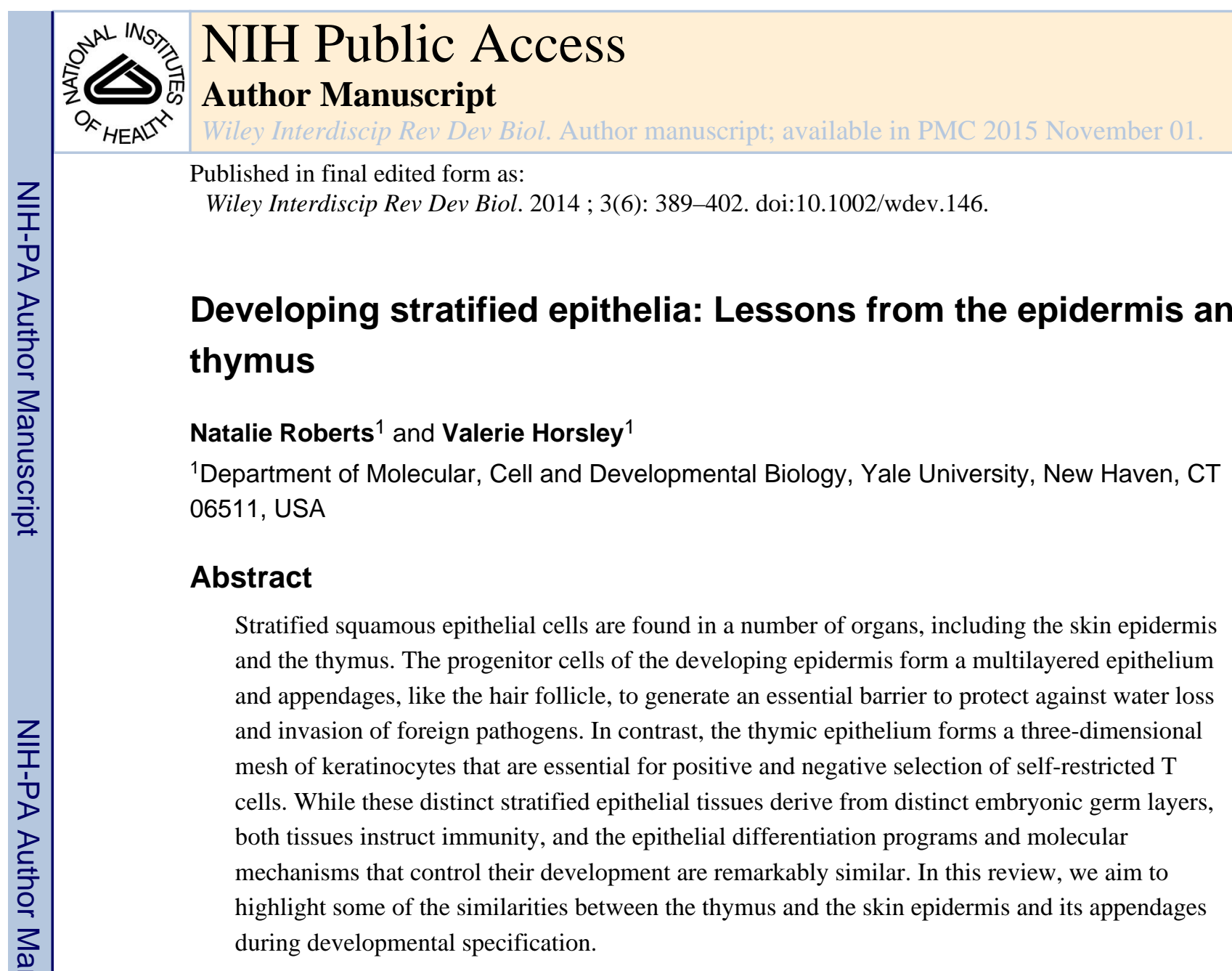

Keywords

Epithelium; Skin; Thymus; Immunity; Development

\title{
Introduction
}

The organization of the mature epidermis generates an essential barrier that is vital for animals to survive the external environment throughout life $^{1}$ (Figure 1A). The epithelium is multi-layered with each layer displaying morphological and biochemical differences in protein expression, including keratins ${ }^{2}$. The inner-most basal layer is composed of proliferative keratin 14 (K14) expressing cells that are intermixed with minor populations of sensory Merkel cells, melanocytes and leukocytes ${ }^{2-4}$. The basal cells secrete components of the extracellular matrix that forms the basement membrane, a separation between the epidermis and the underlying dermis. Basal cells differentiate upward to form the spinous layer that expresses $\mathrm{K} 1 / \mathrm{K} 10$, which is tightly adherent to the basal layer and other surrounding keratinocytes through adherens junctions and desmosomes. An additional suprabasal layer, the granular layer, contains keratinocytes that express loricrin, filaggrin and involucrin proteins, begin to lose their nuclei and generate membrane coating lipid-filled granules called lamellar bodies. Finally, the outermost cornified layer is composed of

Correspondence should be addressed to: Valerie Horsley, valerie.horsley@yale.edu, Dept. of Molecular, Cellular and Developmental Biology, Yale University, 219 Prospect St., Box 208103, New Haven, CT 06520, Tel \#203-436-9126, Fax \#203-432-6161. 
anucleated polyhedral cells that are surrounded by a lipid matrix, which generates a functional barrier. The embryonic basal keratinocytes also form placodes and generate epidermal appendages such as the hair follicle.

In contrast to the epidermis where the distinct epithelial layers are organized on top of a basement membrane ${ }^{5}$, the epithelial cell compartment of the thymus is structured in a threedimensional network (Figure 1B) that is essential for homeostatic maintenance of the peripheral immune system. In its entirety, the thymus is an encapsulated primary lymphoid organ situated above the heart that is comprised of two types of epithelial cells: medullary thymic epithelial cells (mTEC) that express K14 and K5 and cortical thymic epithelial cells (cTEC) that express predominantly $\mathrm{K} 18$ and $\mathrm{K} 8^{6-8}$ (Figure 1B). The cortex fills the outer regions of the thymus and supports $\mathrm{T}$ cell receptor rearrangement and positive selection of $\mathrm{T}$ cells $^{6,9,10}$. In contrast, mTECs reside in the central medulla, and terminally differentiate by progressively expressing the transcriptional regulator, autoimmune regulator (AIRE) followed by involucrin. Involucrin expressing cells form swirled epithelial structures known as Hassall's corpuscles ${ }^{11,12}$.

Despite the differences in the overall organization of the mature epidermal and thymic tissues, several similarities exist between epidermal and thymic epithelium. Similarities were clearly identified by in vitro analysis and comparison of gene and protein expression between human thymic epithelial cells and human keratinocytes ${ }^{13}, 14$. Furthermore, the developmental program that allows mTECs to form Hassall's corpuscles is analogous to that of skin epidermal basal cells as they form cornified cells ${ }^{14}$ (Figures 1 and 2). In fact, the swirled Hassall's corpuscles contain markers similar to differentiated keratinocytes of the epidermis and resemble the keratin pearls in the disorganized squamous cell carcinomas of the epidermis. The differences in organization may arise from the interaction of the thymocytes with TECs during embryonic development since in the absence of thymocytes, TECs reorganize themselves, aligning along the capsule as if it were a basement membrane ${ }^{5}$.

Additional similarities between keratinocytes formed in these two organs are also highlighted by the responsiveness of thymic epithelial cells to the skin tissue environment. Transplantation of proliferative thymic epithelial cells derived from rats into the skin, permitted these cells to form epidermis and skin appendages such as the sebaceous gland and hair follicle ${ }^{2}$. Thus, thymic keratinocytes display plasticity when subjected to an alternative microenvironment ${ }^{15}$.

While the functions of skin and thymic keratinocytes broadly seem quite distinct, both tissues have primary roles in establishing immunity. Thymic epithelial cells create an environment that promotes the expansion, maturation, and specification of immature T cells. Adhesive contacts between these two cell types provides growth factors to developing $\mathrm{T}$ cells and in turn, the $\mathrm{T}$ cell precursors deliver signals that encourage the maturation and differentiation of the epithelial cells. Thus, the development of thymocytes and thymic epithelial cells (TECs) are interdependent processes and this notion of reciprocal signaling has been termed "thymus cross-talk". 
Epidermal keratinocytes are also essential for driving the activation of the innate and adaptive immune system. Keratinocytes produce cytokines that activate different lymphocyte populations collectively known as the "epimmunome"16. Furthermore, tissue injury leads to the induction of keratinocyte 'stress-associated' genes such as ribonucleic acid export $1(\text { Rae } 1)^{17}$ and $H_{60}{ }^{18}$. These stress antigens engage NKG2D (CD314), an immunoreceptor expressed by cells of the innate (natural killer cells and dendritic epidermal $\mathrm{T}$ cells) and adaptive (activated $\mathrm{CD} 8^{+} \mathrm{T}$ cells, and natural killer $\mathrm{T}$ cells) immune system, activating a lymphoid stress-surveillance response ${ }^{19}$. Furthermore, tissue resident memory $\mathrm{T}$ cells develop within the skin where they require the action of the cytokines, Il15 and Tgf $\beta$ that are produced by keratinocytes ${ }^{20}$. These cytokines, not only control their development but also promote the long-term maintenance of this $\mathrm{T}$ cell population. In addition, co-culture of human keratinocytes and naïve $\mathrm{T}$ cells can produce functional self-restricted $\mathrm{T}$ cells ${ }^{21}$, suggesting that skin keratinocytes can promote $\mathrm{T}$ cell development like thymic epithelial cells, though at a low efficiency. Thus, by exploring the shared and distinct mechanisms that instruct the development of these epithelial tissues, this review aims to gain a picture of stratified epithelial formation and how shared cellular and molecular mechanisms may influence the formation of epithelia essential for immunity and barrier function.

\section{Development of the interfollicular epidermis}

During embryogenesis, the mature skin epidermis is established from the developing ectoderm that generates the multi-layered epithelium following a complex and precisely coordinated stratification program ${ }^{2}$. Following gastrulation, a single layer of epidermal cells is generated known as the primitive ectoderm. This undifferentiated, multipotent layer expresses the keratins characteristic of simple epithelia, K8 and K18, 22. While regional differences exist in the timing of keratinocyte specification, after embryonic day (E) 8.5, the murine ectoderm is specified to an epidermal cell fate, indicated by the expression of the transcription factor, $\mathrm{p} 63^{23}$. After E9.5 in the mouse, the epidermal cells commit to a complex epithelial fate, indicated by the expression of K5, K14 and K15.

After this initial commitment step, keratinocytes in the newly established embryonic basal layer initiate the process of stratification at E10.5 giving rise to a second layer of cells, the periderm ${ }^{2}, 24$. The periderm is thought to act as a transient barrier until the cornified layer is formed, since the periderm is shed before birth as the epidermal barrier is acquired ${ }^{2,25}$.

The maturation of the epidermis occurs as the cells asymmetrically divide, stratify and terminally differentiate, culminating in the formation of a multi-layered epidermis $4,22,26,27$. The first layer of intermediate cells initially maintain proliferative capacity prior to exiting the cell cycle, and form differentiated spinous cells with strong expression of K1 and K10. These keratins generate a robust intermediate filament network interlinked with desmosomes ${ }^{1,2,4}$. By E16.5 additional layers of differentiated cells including the granular layer beneath the periderm are generated by the epidermis ${ }^{4}$. Further differentiation is evident at E17.5 by the appearance of filaggrin and the generation of acellular corneocytes, reminiscent of cornified epithelial cells, which create the epithelial barrier. Consequently, by E18.5 the murine epidermis has complete barrier function and is a fully stratified squamous epithelium ${ }^{4}$. Barrier formation is characterized by the establishment of cornified cell 
envelopes that are composed of a rigid scaffold created by the bundling of keratins. These bundles are crosslinked with filaggrin and other structural proteins such as involucrin and loricrin, and surrounded by an insoluble lipid covered exterior ${ }^{4,28}$.

\section{Multipotent epithelial progenitors in the epidermis}

The epithelial progenitor cells of the epidermis are multipotent, giving rise to several lineages including appendages such as the hair follicle, sweat glands and sensory Merkel cells. Prior to stratification of the interfollicular epidermis, epidermal progenitors initiate hair follicle development in response to inductive signals from the mesenchyme. The instructed epithelium generates hair placodes as the underlying mesenchymal cells compact to form dermal condensates, precursors for the dermal papillae that remain associated with the hair follicle. The placodes subsequently grow down into the dermis and generate the multiple lineages of the hair follicle and sebaceous glands, which generate the mature pilosebaceous unit ${ }^{29}$.

An additional lineage derives from epidermal progenitors during development, such as Merkel cells, the sensory cells that aid in the perception of touch. These cells express intermediate filament proteins associated with primitive and simple epithelia, $\mathrm{K} 8$ and $\mathrm{K} 18$, arise between E15 and E17 in mouse skin and are generated by keratin 14 expressing cells $^{30-32}$. The recent identification of the epithelial origin of Merkel cells has initiated the identification of molecular mechanisms that regulate the formation of this lineage including polycomb epigenetic modulators and the transcription factor SRY (sex determining region Y)-box 2 (SOX2) ${ }^{3334}$. Future work further clarifying how epidermal progenitors specify Merkel cells may have implications for the formation of Merkel cell carcinomas.

\section{Thymic epithelial development}

From an entirely distinct developmental origin, thymic epithelial cells arise from the endoderm of the anterior foregut ${ }^{35}$. In a process similar to hair follicle placode formation, the endodermal progenitor cells grow down into the underlying mesenchyme to form the thymic rudiment (Figure 3). The first signs of the budding and outgrowth of the thymic rudiment are morphologically detectable by embryonic day 10-11 (E10-11) in mice, which coincides with the expression of the transcription factor, Forkhead box protein N1 (FOXN1), an essential transcription factor for thymic epithelial development ${ }^{36-38}$. At about $\mathrm{E} 12$, the thymic primordium separates from the endodermal surface of the foregut and begins to migrate towards the anterior chest cavity. At this stage, the epithelial cells express high levels of $\mathrm{K} 8$ and the transcription factor, p63.

At around E12.5, coinciding with hematopoietic cell colonization and prior to vascularization, the immature thymus undergoes further patterning and differentiation ${ }^{7}$. This phase initiates the first signs of morphological medulla-cortex separation as the discrete cortical and medullary areas contain increasingly defined subsets of epithelial cells marked by differential keratin expression ${ }^{39,40}$. 


\section{Bipotent Thymic Epithelial Progenitors}

Defined cortical and medullary epithelial lineages arise from a common progenitor population that forms early during thymic development ${ }^{41,42}$. Ectopic transplantation of isolated E12 thymus lobes demonstrated that progenitor cells exist within the thymic primordium, which have the capacity to generate both cortical and medullary epithelial cells ${ }^{43}, 44$. Furthermore, clonal analysis of individual TECs in chimeric mice, in transplantation studies, or with genetic lineage tracing of $\mathrm{K}^{+} 4^{+}$cells, has demonstrated the presence of a common epithelial precursor with the capacity to generate both cortical and epithelial lineages ${ }^{45,464342}$. Additionally, random reactivation of Foxn1 in individual TECs in Foxn1 null mice, further supported the idea that a single progenitor cell has the ability to generate both cortical and medullary epithelial cells in the postnatal thymus ${ }^{42}$. While bipotent epithelial progenitor cells co-express $\mathrm{K} 5$ and $\mathrm{K} 8^{44,47,48}$ during thymic development, careful analysis of the timing of epithelial cell emergence revealed that cortical epithelial cells are generated prior to medullary epithelial cells and that CD205 ${ }^{+}$ cells have the capacity to generate both cortical and medullary epithelial cells in transplantation experiments ${ }^{49}$. While TECs are able to regenerate postnatally, albeit with diminished efficiency ${ }^{41}$, the lineage relationship between cortical and medullary epithelial progenitors postnatally is not known. Identification of appropriate phenotypic markers is required for the further elucidation of TEC progenitor biology 42,50 .

The generation of mature mTECs during development closely resembles the differentiation program of the interfollicular epidermis (Figure 2). Like basal epidermal keratinocytes, mTEC progenitor cells maintain expression of p63 and K14, while the majority of mTECs downregulate $\mathrm{K} 8$ expression. These proliferative precursor cells generate postmitotic cells that express the transcriptional regulator AIRE and elevate CD80 and MHC class II expression $^{51}$. AIRE expression leads to the ability of mTECs to activate the expression of proteins found in peripheral tissues and to eliminate $\mathrm{T}$ cells that associate with these "selfpeptides" through negative selection ${ }^{52}$. AIRE is also required for the generation of involucrin and filaggrin expressing cells within Hassall's corpuscle-like structures in the medulla ${ }^{53}$. These differentiated epidermal genes are located in a gene complex, and since their expression in the epidermis is controlled by the histone demethylase jumonji domain containing 3 (JMJD3) and the polycomb repressive complex enhancer of zeste homolog 2 (EZH2), AIRE may coordinate with these factors ${ }^{54}$, 55 . Furthermore, while AIRE expression has been reported in cultured human keratinocytes ${ }^{21}$, whether AIRE acts in epidermal keratinocytes to control epithelial function or differentiation is not known.

\section{Molecular regulation of stratified epithelial development}

The molecular control of the development of the epidermis and its appendages or the thymus, individually, has been covered in depth by several recent reviews ${ }^{29,} 3056-58$. Here, we focus on transcriptional regulators and signaling pathways that impact epidermal and thymic epithelial tissues, highlighting similarities and differences in the two epithelial lineages (Figure 3). 


\section{Transcriptional regulation}

p63: essential regulator of stratified epithelium-The development of both epidermal and thymic epithelium requires the expression of the p53 family transcription factor, p $63^{2,59,60}$, which is expressed early in the development of both epithelial lineages ${ }^{23,60,61}$. Epidermal development is severely abrogated in loss of function mouse models for $p 63$ with few keratinocytes and lack of stratification resulting in rapid dehydration and early postnatal lethality of $p 63^{-/-}$mice ${ }^{62,63}$. A similar epithelial phenotype occurs in the thymus of $p 63^{-/-}$mice, which displayed thymic atrophy due to defects in the proliferative rate of thymic epithelial cells. While alternative promoter usage at the p63 locus, produces two isoforms of p63, a transactivating form (TAp63) and an isoform lacking the $\mathrm{N}$ terminal domain ( $\Delta \mathrm{Np} 63$ ), isoform-specific knockout mice have revealed that $\Delta \mathrm{Np} 63$ is the major isoform responsible for maintenance of epidermal epithelium ${ }^{64,65}$. Complementation of $p 63^{-/-}$mice with mice expressing $\Delta \mathrm{Np} 63$ driven by the $\mathrm{K} 5$ promoter partially increased thymic cellularity, implicating $\Delta \mathrm{Np} 63$ as a major isoform in the thymus as well. Since p63 is expressed prior to K14 expression and regulates K14 expression ${ }^{23,} 66$ the function of p63 prior to K5 expression may be required for thymic function.

The precise role of p63 in epidermal development is likely complex and is still not fully understood. Clues from both epidermal and thymic epithelial studies have implicated FGF and Notch signaling downstream of $\mathrm{p} 63^{67}$. Several human patients with ectodermal dysplasias have mutations in the $p 63$ gene and knockin mouse models harboring a missense mutation in the p63 SAM domain display skin and cleft palate phenotypes ${ }^{68}$. Mice lacking Fgfr $2 \beta$ display similar ectodermal phenotypes as human patients with ectodermal dysplasias $^{69}$ as well as defects in thymic development, which is halted at E12 ${ }^{70}$. Indeed, $p 63$ null embryos lack FGF receptor $2 \beta$ (FGFR2 $\beta$ ) in the epidermis ${ }^{71}$ and thymus ${ }^{67}$, suggesting that FGF signaling in part is a mechanism by which p63 controls stratified epithelial development by promoting proliferation of progenitor cells. Additional mechanisms by which FGF signaling regulates the development of these epithelia are discussed later in this review.

FOXN1: differential roles in stratified epithelial cells-Another key transcription factor for both epidermal and thymic epithelial development is FOXN1, a member of the Fox family of transcription factors that are involved in development, metabolism and aging. FOXN1 is expressed in the mature thymic and skin epithelia; however, it seems to have differential roles in these tissues. In both humans and mice, the Foxnl gene is comprised of eight coding exons and utilizes two alternative first exons in a tissue-specific fashion ${ }^{72,73}$. Although both promoters appear to be active in keratinocytes of the skin (albeit at different levels), only the most upstream element is active in the thymus, which may explain some of the differential roles this gene plays within these two tissues.

In the epidermis, FOXN1 is expressed within differentiated epidermal and follicular cells. Mice lacking Foxnl display defects in hair follicle differentiation, resulting in alopecia as well as defects in epidermal keratinocyte differentiation, where keratinocytes in vitro differentiate spontaneously in proliferative conditions ${ }^{7475}$. 
In contrast, FOXN1 acts early in thymus development where it promotes TEC progenitor proliferation and directs specification of thymic epithelial precursor cells to cortical and medullary lineages ${ }^{76-78}$. In the absence of Foxn1 expression, the development of early epithelial precursor cells is reversibly arrested, while restoration of FOXN1 expression can induce normal differentiation ${ }^{42}$. While the precise mechanisms by which FOXN1 promotes thymic epithelial differentiation are unknown, this transcription factor has been implicated in controlling expression of several other transcription factors important for TEC development including paired box protein 1 (PAX1), PAX9 and homeobox A3 (HOXA3) 79 . Interestingly, it has been hypothesized that HOXA3 acts upstream of PAX transcription factors and may control the separation of the thymus primordia from the pharynx and their subsequent migration towards the mediastinum ${ }^{80,81}$. Hoxa 3 is required for the development of structures in the pharyngeal region, leading to a loss of thymus formation in Hoxa 3 null mice $^{82}$. In epidermal keratinocytes, HOXA3 promoted the migration of keratinocytes during wound healing ${ }^{83}$.

The regulation of FOXN1 expression by the retinoblastoma (RB) family of proteins (RB, p107 and p130) revealed a role for FOXN1 in the regulation of TEC proliferation ${ }^{78}$. Genetic deletion of $R B$ leads to increased TEC proliferation, resulting in enlarged thymic lobes and inhibition of thymic atrophy associated with age. This phenotype is similar to mice lacking both $R B$ and $p 107$, which displayed hyperplasia of the epidermis due to increased proliferation and differentiation ${ }^{84}$. In the thymus, RB promotes the transcription of Foxn1 expression, which is required for TEC expansion in $R B$ mutant mice in vivo. These data are consistent with the requirement of FOXN1 for homeostatic control of postnatal TECs ${ }^{85}$, 86, and indicate that FOXN1 promotes both proliferation and differentiation of TEC progenitors. It is unknown whether RB family members regulate Foxnl expression in epidermal keratinocytes to control epidermal homeostasis.

TBX1: development and regeneration of epithelial lineages-The T box gene $T b x l$, is another transcription factor that is shared between epidermal progenitor cells in the epidermis and thymus. In the epidermis, TBX1 is highly expressed within the developing hair placode and becomes restricted to hair follicle stem cells and their progeny ${ }^{87}$. Conditional deletion of $\mathrm{Tbxl}$ in $\mathrm{K}_{1} 4^{+}$cells resulted in loss of hair follicle stem cell renewal following several rounds of depilation. During thymus development, $T b x l$ is expressed early in the pharyngeal endoderm and mesoderm ${ }^{88}$. Complete loss of $T b x l$ results in a loss of thymic epithelial development, which phenocopies DiGeorge syndrome ${ }^{89-91}$, a genetic disease caused by heterozygous monoallelic microdeletion within human chromosome 22q11, clinically recognized by malformations of pharyngeal arch arteries and heart, parathyroid hypoplasia, and absence or ectopic location of the thymus ${ }^{92}$. TBX1 seems to be necessary in both the endoderm and the mesoderm to control thymic development. Furthermore, microarray analysis on E9.5 Tbxl null embryos identified several putative Tbx target genes including $F g f 8^{93}$ and $\operatorname{Pax} 9^{94}$. Whether like in the epidermis, TBX1 regulates TEC maintenance postnatally remains to be determined. 


\section{Regulation by signaling pathways}

FGF signaling: building epithelial buds-A major regulator of both hair follicle placode formation and thymic epithelial development is FGF signaling. In both tissues, FGF7 and FGF10 are expressed by the surrounding mesenchyme ${ }^{7095}$. Deletion of the receptor for these ligands, FGFR2 isoform IIIb resulted in a block in thymic epithelium development after rudiment formation. These defects were similar to the phenotype of Fgfr2IIIb null mice in the thymus, which displayed a hypoplastic interfollicular epidermis and fewer and retarded hair follicle placode formation ${ }^{96,97}$. Unlike the inability of the thymus to progress beyond a rudiment, hair follicles formed in grafted skin of Fgfr2IIIb null mice, indicating that the hair defect was not completely abrogated. These studies revealed the importance of mesenchymal expression of FGFs to promote epithelial proliferation and invagination to generate mature thymic rudiments and epidermal hair placodes.

\section{WNT signaling: promoting epithelial progenitor proliferation and fate}

determination-WNT signaling regulates development of several tissues and is involved in tumor formation in several epithelial tissues ${ }^{98}$. When WNT ligands bind to frizzled receptors, in coordination with low-density lipoprotein receptor related proteins (LRPs), they transmit intercellular signals which ultimately stabilize cytoplasmic $\beta$-catenin (CTNNB1), allowing $\beta$-catenin to translocate to the nucleus where it complexes with the lymphoid enhancing factor/T cell factor (LEF/TCF) family transcription factors, to regulate gene expression.

In the epidermis, WNT signaling is activated in the IFE, placodes during hair follicle formation and during hair shaft differentiation ${ }^{99-101}$. During embryogenesis, WNT signaling specifies epidermal fate ${ }^{102}$ and hair follicle placode initiation. In the postnatal/adult setting several studies have implicated WNT signaling in the control of hair follicle formation. Deletion of Ctnnb1 or expression of Wnt inhibitor, DKK1 in an epithelial specific manner resulted in a lack of several epidermal appendages including hair follicles ${ }^{103,} 104$. Furthermore, expression of a dominant active form of $\beta$-catenin in basal keratinocytes induced ectopic hair follicle formation ${ }^{105}$. Deletion of Lefl in mice reduced hair follicle formation but not a complete ablation ${ }^{106}$, suggesting that $\beta$-catenin may act with other factors to fully control hair follicle formation and development.

In addition to its role in the hair follicle, recent work suggested that WNT signaling controls IFE proliferation ${ }^{100,101}$. Mice, in which Ctnnbl was deleted in a subset of epidermal cells, using an inducible form of Cre recombinase driven by the Axin 2 promoter, displayed a thinner epidermal compartment due to defects in proliferation of IFE progenitor cells. This function of WNT signaling is similar to its role in hair follicle progenitor cells, where Ctnnbl is required for their proliferation during hair growth ${ }^{100}$.

Less is understood about the role of WNT signaling in thymic epithelial development. TECs and T cells express WNT ligands during thymic development where they can activate FOXN1 expression in cultured TECs ${ }^{107}$. Intriguingly, abnormal cortical TEC architecture has been identified in mice lacking kringle containing transmembrane protein 1 (Kremenl), a negative regulator of WNT signaling. In addition, cortical TECs have been shown to express a range of WNT molecules, including WNT4 and WNT10b ${ }^{108,109}$. Additionally, 
mice lacking adenomatous polyposis coli (Apc), a major component of the protein complex that degrades $\beta$-catenin in the absence of WNT ligands, in K14-expressing keratinocytes displayed enhanced WNT signaling in the thymus and developed smaller thymic lobes with reduced epithelial proliferation and increased numbers of K14 expressing epithelial cells ${ }^{110}$. Whether this thymic phenotype is solely due to the action of WNT signaling in the thymus or other roles of APC is not known. Furthermore, whether WNT signaling promotes proliferation of TECs and/or terminal differentiation similar to its role in the IFE and hair follicle will be an interesting area of future investigation.

Eph/ephrin signaling: organizing epithelia-Eph receptors, which bind to membrane bound ephrins, represent the largest group of receptor tyrosine kinases in mammals ${ }^{111} 112$. Ephs are classified into two subfamilies, EphA and EphB, depending on their binding preference to glycosylphophatidylinositol (GPI)-anchored ephrins A or transmembrane ephrins B ligands, respectively 111,113 . In both the epidermis and thymus, Eph receptors and ephrins are compartmentalized with differential expression in distinct cell subsets ${ }^{114}$. In the interfollicular epidermis, ephrinA proteins are concentrated in basal keratinocytes while EphA receptors can be found within all viable layers of the epidermis ${ }^{115}$. Inhibition of Eph/ ephrin signaling complexes may negatively regulate keratinocyte proliferation ${ }^{116}$, which may be relevant for tumorigenesis in the skin given the enhanced tumorigenesis of EphA2 null mice ${ }^{117}$. Furthermore, EphA2 has been implicated in the terminal differentiation of epidermal keratinocytes ${ }^{115}$ perhaps by promoting desmosome maturation ${ }^{115,118}$. While the

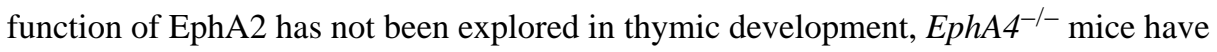
reduced TEC cell numbers and a smaller and disorganized thymic cortex and medulla ${ }^{119}$, suggesting a role in proliferation. Whether EphA4 alters desmosome formation or other adhesion or differentiation mechanisms to control TEC organization would be an interesting future area of study.

EphB family members also regulate epidermal and thymic epithelial development. EphB2 and EphB3 and their ligands ephrinB1 and ephrinB2 are expressed on both thymic epithelial cells and thymocytes ${ }^{120}$. Conditional deletion of ephrinB1 and ephrinB2 in epithelial cells led to alterations in skin development including short hair and premature eye opening ${ }^{112}$. Furthermore, these mice exhibited abnormal thymic epithelial architecture, characterized by a reduced size and a higher proportion of $\mathrm{K}^{+} \mathrm{K} 8^{+}$presumptive thymic epithelial progenitor cells and thymic epithelial cysts ${ }^{112}$. Since EphA4 can bind to ephrinB ligands ${ }^{121}$, it is possible that some of the thymic phenotypes in the ephrinB1/B2 and EphA4 null mice may be shared.

BMP signaling: determining epithelial fate-Bone morphogenetic proteins (BMPs) are members of the transforming growth factor $\beta$ (TGF $\beta$ ) superfamily that play roles in cellfate determination and developmental patterning of many tissues ${ }^{122,123}$. BMPs bind to heterodimeric receptors and transmit signals through SMAD transcriptional complexes. In epidermal development, BMPs act early in the ectoderm to drive specification to the epidermal keratinocyte lineage ${ }^{2,124,125}$. Later in epidermal appendage development, inhibition of BMP signaling promotes hair placode formation ${ }^{126}$. Noggin, a BMP antagonist, is expressed by mesenchymal cells and is thought to decrease BMP signaling, which 
activates the WNT responsive transcription factor $\mathrm{LEF} 1^{127}$ and induces hair follicle fate. Later in hair follicle formation, differentiation of hair follicle matrix cells requires active BMP signaling ${ }^{128}$.

In the thymus, BMP signaling is required for proper epithelial development as mice expressing noggin in FOXN1 expressing progenitor cells, formed small thymic lobes with reduced epithelial cell number and mislocalization in the neck, rather than above the heart $^{129}$. The expression of Bmp4 in the thymic anlage and mesenchyme suggests bidirectional signaling between epithelial mesenchyme ${ }^{129,130}$. Whether BMPs control thymic anlage development into the mesenchyme, similar to its role in the epidermal placode formation, or later stages of epithelial development is not known.

Notch signaling: determining epithelial fate-The canonical Notch signaling pathway regulates several steps of epidermal specification. During ectoderm specification, Notch signaling suppresses epidermal fate by blocking p63 expression ${ }^{23}$. Later during IFE differentiation, Notch signaling is activated in spinous cells and conditional deletion of the transcription factor downstream of Notch signaling, Rbpj in the skin, blocked spinous cell formation $^{131}$. A similar phenotype occured in mice lacking Hes 1, a Notch target gene ${ }^{132}$. Furthermore, Notchl-null mice displayed abnormal epidermal proliferation and differentiation ${ }^{133}$. While Notch signaling between TECs and $\mathrm{T}$ cells can regulate $\mathrm{T}$ cell development ${ }^{134}$, whether intrinsic Notch signaling regulates mTEC differentiation in a similar manner, has not been explored to date.

\section{Conclusion}

The epidermis and its appendages have become an excellent model system to explore the cellular and molecular mechanisms by which epithelial tissues develop and regenerate ${ }^{29}$. In this review, we highlight significant advances that emphasize similarities between the development of epidermal and thymic epithelial tissues. Two major themes emerge from these comparisons: first, the similarities between hair follicle placode morphogenesis and that of the early thymic anlage development (Figure 3). These two structures grow down into the underlying mesenchyme, express similar transcriptional regulators and require cues from mesenchymal cells to drive morphogenesis (Figure 3A). A second theme emerges in the shared cell specification and differentiation programs that drive the formation of epithelial cells in the skin and thymus (Figure 3B).

In the future, it will be interesting to determine if parallels exist between the postnatal maintenance of epithelial progenitor cells in the epidermis and thymus. Recent work has highlighted the importance of epithelial stem cells in the maintenance of the interfollicular epidermis and hair follicles ${ }^{135}$. However, the identity of such a cell in the thymus has remained elusive. Since age-associated thymic atrophy leads to a decline in naïve $\mathrm{T}$ cell output to the periphery and a reduced ability of the adult immune system to respond to infection and vaccination ${ }^{136}$, it will be interesting to understand if mechanisms that maintain epidermal stem cells in the skin display altered function in thymic epithelial progenitor cells. In particular, the role of epigenetic regulation of chromatin and histones within the 
epidermis has been shown to be required for maintenance of the epidermis ${ }^{137,138}$ but their role in the thymus has not been explored to date.

Another interesting avenue for future investigation will be the role of the mesenchyme in controlling epithelial development and regeneration in both tissues. As discussed above, several studies have highlighted the importance of mesenchymal-epithelial interactions during thymic and hair follicle development and regeneration including WNT and FGF signaling. While recent work suggested that epidermal fibroblasts share a common progenitor during development ${ }^{139}$, the mechanisms that control development of fibroblast lineages in both the epidermis and thymus are largely unknown. Since epithelial function can be disrupted by skin fibrosis and fibroadipogenic cells in the thymus with disease or age, the generation of genetic tools (e.g. Cre-loxP technology) that permit the study of dermal cell populations will facilitate our understanding of these changes in epithelial mesenchymal composition and how they alter epithelial tissues.

In the last several years, skin and thymic tissue development have been fruitful systems for understanding how epithelial cells develop and the molecular mechanisms that drive these processes. Advancing our understanding of epithelial development will help design effective molecular and cellular methods to treat skin and immune disorders, where the epithelium is dysfunctional.

\section{Acknowledgments}

We thank Horsley lab members for critical reading of the manuscript. V.H. is a Pew Scholar in Biomedical Research and is funded by the NIH (AR060295) and the Connecticut Department of Public Health (12SCBYALE01).

\section{References}

1. Blanpain C, Fuchs E. Epidermal homeostasis: a balancing act of stem cells in the skin. Nature reviews Molecular cell biology. 2009; 10:207-217.

2. Koster MI, Roop DR. Mechanisms regulating epithelial stratification. Annual review of cell and developmental biology. 2007; 23:93-113.

3. McMillan JR, Akiyama M, Shimizu H. Epidermal basement membrane zone components: ultrastructural distribution and molecular interactions. Journal of dermatological science. 2003; 31:169-177. [PubMed: 12727020]

4. Nagarajan P, Romano RA, Sinha S. Transcriptional control of the differentiation program of interfollicular epidermal keratinocytes. Critical reviews in eukaryotic gene expression. 2008; 18:5779. [PubMed: 18197786]

5. van Ewijk W, et al. Thymic microenvironments, 3-D versus 2-D? Semin Immunol. 1999; 11:57-64. [PubMed: 9950752]

6. Anderson G, et al. Establishment and functioning of intrathymic microenvironments. Immunol Rev. 2006; 209:10-27. [PubMed: 16448531]

7. Rodewald HR. Thymus organogenesis. Annu Rev Immunol. 2008; 26:355-388. [PubMed: 18304000]

8. Alves NL, et al. Serial progression of cortical and medullary thymic epithelial microenvironments. Eur J Immunol. 2014; 44:16-22. [PubMed: 24214487]

9. Boyd RL, et al. The thymic microenvironment. Immunol Today. 1993; 14:445-459. [PubMed: 8216723]

10. Takahama Y. Journey through the thymus: stromal guides for T-cell development and selection. Nat Rev Immunol. 2006; 6:127-135. [PubMed: 16491137] 
11. Favre A. Identification of filaggrin in Hassall's corpuscle by histochemical and immunohistochemical methods. Acta anatomica. 1989; 135:71-76. [PubMed: 2750463]

12. Hale LP, Markert ML. Corticosteroids regulate epithelial cell differentiation and Hassall body formation in the human thymus. J Immunol. 2004; 172:617-624. [PubMed: 14688374]

13. Patel DD, Whichard LP, Radcliff G, Denning SM, Haynes BF. Characterization of human thymic epithelial cell surface antigens: phenotypic similarity of thymic epithelial cells to epidermal keratinocytes. Journal of clinical immunology. 1995; 15:80-92. [PubMed: 7559912]

14. Lobach DF, Haynes BF. Ontogeny of the human thymus during fetal development. Journal of clinical immunology. 1987; 7:81-97. [PubMed: 2437143]

15. Bonfanti $\mathrm{P}$, et al. Microenvironmental reprogramming of thymic epithelial cells to skin multipotent stem cells. Nature. 2010; 466:978-982. [PubMed: 20725041]

16. Swamy M, Jamora C, Havran W, Hayday A. Epithelial decision makers: in search of the 'epimmunome'. Nat Immunol. 2010; 11:656-665. [PubMed: 20644571]

17. Gasser S, Orsulic S, Brown EJ, Raulet DH. The DNA damage pathway regulates innate immune system ligands of the NKG2D receptor. Nature. 2005; 436:1186-1190. [PubMed: 15995699]

18. Whang MI, Guerra N, Raulet DH. Costimulation of dendritic epidermal gammadelta T cells by a new NKG2D ligand expressed specifically in the skin. J Immunol. 2009; 182:4557-4564. [PubMed: 19342629]

19. Hayday AC. Gammadelta T cells and the lymphoid stress-surveillance response. Immunity. 2009; 31:184-196. [PubMed: 19699170]

20. Mackay LK, et al. The developmental pathway for CD103(+)CD8+ tissue-resident memory T cells of skin. Nat Immunol. 2013; 14:1294-1301. [PubMed: 24162776]

21. Clark RA, Yamanaka K, Bai M, Dowgiert R, Kupper TS. Human skin cells support thymusindependent $\mathrm{T}$ cell development. The Journal of clinical investigation. 2005; 115:3239-3249. [PubMed: 16224538]

22. McGowan KM, Coulombe PA. Onset of keratin 17 expression coincides with the definition of major epithelial lineages during skin development. The Journal of cell biology. 1998; 143:469486. [PubMed: 9786956]

23. Tadeu AM, Horsley V. Notch signaling represses p63 expression in the developing surface ectoderm. Development. 2013; 140:3777-3786. [PubMed: 23924630]

24. M'Boneko V, Merker HJ. Development and morphology of the periderm of mouse embryos (days 9-12 of gestation). Acta anatomica. 1988; 133:325-336. [PubMed: 3227794]

25. Hardman MJ, Sisi P, Banbury DN, Byrne C. Patterned acquisition of skin barrier function during development. Development. 1998; 125:1541-1552. [PubMed: 9502735]

26. Byrne C, Tainsky M, Fuchs E. Programming gene expression in developing epidermis. Development. 1994; 120:2369-2383. [PubMed: 7525178]

27. Lechler T, Fuchs E. Asymmetric cell divisions promote stratification and differentiation of mammalian skin. Nature. 2005; 437:275-280. [PubMed: 16094321]

28. Steven AC, Steinert PM. Protein composition of cornified cell envelopes of epidermal keratinocytes. Journal of cell science. 1994; 107 (Pt 2):693-700. [PubMed: 8207091]

29. Blanpain C, Fuchs E. Epidermal stem cells of the skin. Annual review of cell and developmental biology. 2006; 22:339-373.

30. Van Keymeulen A, et al. Epidermal progenitors give rise to Merkel cells during embryonic development and adult homeostasis. The Journal of cell biology. 2009; 187:91-100. [PubMed: 19786578]

31. Woo SH, Stumpfova M, Jensen UB, Lumpkin EA, Owens DM. Identification of epidermal progenitors for the Merkel cell lineage. Development. 2010; 137:3965-3971. [PubMed: 21041368]

32. Morrison KM, Miesegaes GR, Lumpkin EA, Maricich SM. Mammalian Merkel cells are descended from the epidermal lineage. Developmental biology. 2009; 336:76-83. [PubMed: 19782676] 
33. Lesko MH, Driskell RR, Kretzschmar K, Goldie SJ, Watt FM. Sox 2 modulates the function of two distinct cell lineages in mouse skin. Developmental biology. 2013; 382:15-26. [PubMed: 23948231]

34. Bardot ES, et al. Polycomb subunits Ezh1 and Ezh2 regulate the Merkel cell differentiation program in skin stem cells. The EMBO journal. 2013; 32:1990-2000. [PubMed: 23673358]

35. Boehm T. Thymus development and function. Curr Opin Immunol. 2008

36. Nehls M, Pfeifer D, Schorpp M, Hedrich H, Boehm T. New member of the winged-helix protein family disrupted in mouse and rat nude mutations. Nature. 1994; 372:103-107. [PubMed: 7969402]

37. Nehls M, et al. Two genetically separable steps in the differentiation of thymic epithelium. Science. 1996; 272:886-889. [PubMed: 8629026]

38. Gunther T, et al. Genetic ablation of parathyroid glands reveals another source of parathyroid hormone. Nature. 2000; 406:199-203. [PubMed: 10910362]

39. Anderson G, Jenkinson EJ. Lymphostromal interactions in thymic development and function. Nat Rev Immunol. 2001; 1:31-40. [PubMed: 11905812]

40. Hollander G, et al. Cellular and molecular events during early thymus development. Immunol Rev. 2006; 209:28-46. [PubMed: 16448532]

41. Rossi SW, et al. Redefining epithelial progenitor potential in the developing thymus. Eur J Immunol. 2007; 37:2411-2418. [PubMed: 17694573]

42. Bleul CC, et al. Formation of a functional thymus initiated by a postnatal epithelial progenitor cell. Nature. 2006; 441:992-996. [PubMed: 16791198]

43. Rossi SW, Jenkinson WE, Anderson G, Jenkinson EJ. Clonal analysis reveals a common progenitor for thymic cortical and medullary epithelium. Nature. 2006; 441:988-991. [PubMed: 16791197]

44. Bennett AR, et al. Identification and characterization of thymic epithelial progenitor cells. Immunity. 2002; 16:803-814. [PubMed: 12121662]

45. Rodewald HR, Paul S, Haller C, Bluethmann H, Blum C. Thymus medulla consisting of epithelial islets each derived from a single progenitor. Nature. 2001; 414:763-768. [PubMed: 11742403]

46. Gray DH, et al. Controlling the thymic microenvironment. Curr Opin Immunol. 2005; 17:137-143. [PubMed: 15766672]

47. Klug DB, et al. Interdependence of cortical thymic epithelial cell differentiation and T-lineage commitment. Proc Natl Acad Sci U S A. 1998; 95:11822-11827. [PubMed: 9751749]

48. Gill J, Malin M, Hollander GA, Boyd R. Generation of a complete thymic microenvironment by MTS24(+) thymic epithelial cells. Nat Immunol. 2002; 3:635-642. [PubMed: 12068292]

49. Baik S, Jenkinson EJ, Lane PJ, Anderson G, Jenkinson WE. Generation of both cortical and Aire(+) medullary thymic epithelial compartments from CD205(+) progenitors. Eur J Immunol. 2013; 43:589-594. [PubMed: 23299414]

50. Anderson G, Jenkinson EJ, Rodewald HR. A roadmap for thymic epithelial cell development. Eur J Immunol. 2009; 39:1694-1699. [PubMed: 19582736]

51. Gray D, Abramson J, Benoist C, Mathis D. Proliferative arrest and rapid turnover of thymic epithelial cells expressing Aire. J Exp Med. 2007; 204:2521-2528. [PubMed: 17908938]

52. Alves NL, Huntington ND, Rodewald HR, Di Santo JP. Thymic epithelial cells: the multi-tasking framework of the T cell "cradle". Trends Immunol. 2009; 30:468-474. [PubMed: 19781995]

53. Odaka C, et al. TGF-beta type II receptor expression in thymic epithelial cells inhibits the development of Hassall's corpuscles in mice. Int Immunol. 2013; 25:633-642. [PubMed: 23929912]

54. Ezhkova E, et al. Ezh2 orchestrates gene expression for the stepwise differentiation of tissuespecific stem cells. Cell. 2009; 136:1122-1135. [PubMed: 19303854]

55. Sen GL, Webster DE, Barragan DI, Chang HY, Khavari PA. Control of differentiation in a selfrenewing mammalian tissue by the histone demethylase JMJD3. Genes Dev. 2008; 22:1865-1870. [PubMed: 18628393]

56. Biggs LC, Mikkola ML. Early inductive events in ectodermal appendage morphogenesis. Seminars in cell \& developmental biology. 2014

Wiley Interdiscip Rev Dev Biol. Author manuscript; available in PMC 2015 November 01. 
57. Manley NR, Richie ER, Blackburn CC, Condie BG, Sage J. Structure and function of the thymic microenvironment. Frontiers in bioscience. 2011; 16:2461-2477.

58. Chew-Li Soh, JMC.; Richard, L.; Boyd Ann, P. Chidgey Epithelial Stem Cells and the Development of the Thymus, Parathyroid, and Skin. In: Rajasekhar, MCVVK., editor. Stem Cell Biology and Regenerative Medicine. Humana Press, a part of Springer Science+Business Media; 2009. p. 405-437.

59. Green H, Easley K, Iuchi S. Marker succession during the development of keratinocytes from cultured human embryonic stem cells. Proc Natl Acad Sci U S A. 2003; 100:15625-15630. [PubMed: 14663151]

60. Senoo M, Pinto F, Crum CP, McKeon F. p63 Is essential for the proliferative potential of stem cells in stratified epithelia. Cell. 2007; 129:523-536. [PubMed: 17482546]

61. Koster MI, Kim S, Huang J, Williams T, Roop DR. TAp63alpha induces AP-2gamma as an early event in epidermal morphogenesis. Developmental biology. 2006; 289:253-261. [PubMed: 16324689]

62. Mills AA, et al. p63 is a p53 homologue required for limb and epidermal morphogenesis. Nature. 1999; 398:708-713. [PubMed: 10227293]

63. Yang A, et al. p63 is essential for regenerative proliferation in limb, craniofacial and epithelial development. Nature. 1999; 398:714-718. [PubMed: 10227294]

64. Su X, et al. TAp63 prevents premature aging by promoting adult stem cell maintenance. Cell Stem Cell. 2009; 5:64-75. [PubMed: 19570515]

65. Romano RA, et al. DeltaNp63 knockout mice reveal its indispensable role as a master regulator of epithelial development and differentiation. Development. 2012; 139:772-782. [PubMed: 22274697]

66. Romano RA, Birkaya B, Sinha S. A functional enhancer of keratin14 is a direct transcriptional target of deltaNp63. The Journal of investigative dermatology. 2007; 127:1175-1186. [PubMed: 17159913]

67. Candi E, et al. DeltaNp63 regulates thymic development through enhanced expression of FgfR2 and Jag2. Proc Natl Acad Sci U S A. 2007; 104:11999-12004. [PubMed: 17626181]

68. Ferone G, et al. Mutant p63 causes defective expansion of ectodermal progenitor cells and impaired FGF signalling in AEC syndrome. EMBO molecular medicine. 2012; 4:192-205. [PubMed: 22247000]

69. Rice R, et al. Disruption of Fgf10/Fgfr2b-coordinated epithelial-mesenchymal interactions causes cleft palate. The Journal of clinical investigation. 2004; 113:1692-1700. [PubMed: 15199404]

70. Revest JM, Suniara RK, Kerr K, Owen JJ, Dickson C. Development of the thymus requires signaling through the fibroblast growth factor receptor R2-IIIb. J Immunol. 2001; 167:1954-1961. [PubMed: 11489975]

71. Laurikkala J, et al. p63 regulates multiple signalling pathways required for ectodermal organogenesis and differentiation. Development. 2006; 133:1553-1563. [PubMed: 16524929]

72. Schorpp M, Hofmann M, Dear TN, Boehm T. Characterization of mouse and human nude genes. Immunogenetics. 1997; 46:509-515. [PubMed: 9321431]

73. Cunliffe VT, Furley AJ, Keenan D. Complete rescue of the nude mutant phenotype by a wild-type Foxn1 transgene. Mammalian genome: official journal of the International Mammalian Genome Society. 2002; 13:245-252. [PubMed: 12016512]

74. Brissette JL, Li J, Kamimura J, Lee D, Dotto GP. The product of the mouse nude locus, Whn, regulates the balance between epithelial cell growth and differentiation. Genes Dev. 1996; 10:2212-2221. [PubMed: 8804315]

75. Baxter RM, Brissette JL. Role of the nude gene in epithelial terminal differentiation. The Journal of investigative dermatology. 2002; 118:303-309. [PubMed: 11841548]

76. Shakib S, et al. Checkpoints in the development of thymic cortical epithelial cells. J Immunol. 2009; 182:130-137. [PubMed: 19109143]

77. Ciofani M, Zuniga-Pflucker JC. The thymus as an inductive site for T lymphopoiesis. Annu Rev Cell Dev Biol. 2007; 23:463-493. [PubMed: 17506693]

Wiley Interdiscip Rev Dev Biol. Author manuscript; available in PMC 2015 November 01. 
78. Garfin PM, et al. Inactivation of the RB family prevents thymus involution and promotes thymic function by direct control of Foxn1 expression. J Exp Med. 2013; 210:1087-1097. [PubMed: 23669396]

79. Romano R, et al. FOXN1: A Master Regulator Gene of Thymic Epithelial Development Program. Frontiers in immunology. 2013; 4:187. [PubMed: 23874334]

80. Hetzer-Egger $\mathrm{C}$, et al. Thymopoiesis requires Pax9 function in thymic epithelial cells. Eur $\mathbf{J}$ Immunol. 2002; 32:1175-1181. [PubMed: 11932925]

81. Su D, Ellis S, Napier A, Lee K, Manley NR. Hoxa3 and pax1 regulate epithelial cell death and proliferation during thymus and parathyroid organogenesis. Dev Biol. 2001; 236:316-329. [PubMed: 11476574]

82. Manley NR, Capecchi MR. The role of Hoxa-3 in mouse thymus and thyroid development. Development. 1995; 121:1989-2003. [PubMed: 7635047]

83. Mace KA, Hansen SL, Myers C, Young DM, Boudreau N. HOXA3 induces cell migration in endothelial and epithelial cells promoting angiogenesis and wound repair. Journal of cell science. 2005; 118:2567-2577. [PubMed: 15914537]

84. Ruiz S, et al. Unique and overlapping functions of pRb and p107 in the control of proliferation and differentiation in epidermis. Development. 2004; 131:2737-2748. [PubMed: 15148303]

85. Chen L, Xiao S, Manley NR. Foxn1 is required to maintain the postnatal thymic microenvironment in a dosage-sensitive manner. Blood. 2009; 113:567-574. [PubMed: 18978204]

86. Cheng L, et al. Postnatal tissue-specific disruption of transcription factor FoxN1 triggers acute thymic atrophy. J Biol Chem. 2010; 285:5836-5847. [PubMed: 19955175]

87. Chen T, et al. An RNA interference screen uncovers a new molecule in stem cell self-renewal and long-term regeneration. Nature. 2012; 485:104-108. [PubMed: 22495305]

88. Chapman DL, et al. Expression of the T-box family genes, Tbx1-Tbx5, during early mouse development. Developmental dynamics: an official publication of the American Association of Anatomists. 1996; 206:379-390. [PubMed: 8853987]

89. Jerome LA, Papaioannou VE. DiGeorge syndrome phenotype in mice mutant for the T-box gene, Tbx1. Nature genetics. 2001; 27:286-291. [PubMed: 11242110]

90. Packham EA, Brook JD. T-box genes in human disorders. Hum Mol Genet. 2003; 12(Spec No 1):R37-44. [PubMed: 12668595]

91. Lindsay EA, et al. Tbx1 haploinsufficieny in the DiGeorge syndrome region causes aortic arch defects in mice. Nature. 2001; 410:97-101. [PubMed: 11242049]

92. Naiche LA, Harrelson Z, Kelly RG, Papaioannou VE. T-box genes in vertebrate development. Annu Rev Genet. 2005; 39:219-239. [PubMed: 16285859]

93. Vitelli F, et al. A genetic link between Tbx1 and fibroblast growth factor signaling. Development. 2002; 129:4605-4611. [PubMed: 12223416]

94. Ivins S, et al. Microarray analysis detects differentially expressed genes in the pharyngeal region of mice lacking Tbx1. Dev Biol. 2005; 285:554-569. [PubMed: 16109395]

95. De Moerlooze L, et al. An important role for the IIIb isoform of fibroblast growth factor receptor 2 (FGFR2) in mesenchymal-epithelial signalling during mouse organogenesis. Development. 2000; 127:483-492. [PubMed: 10631169]

96. Petiot A, et al. A crucial role for Fgfr2-IIIb signalling in epidermal development and hair follicle patterning. Development. 2003; 130:5493-5501. [PubMed: 14530295]

97. Richardson GD, et al. KGF and EGF signalling block hair follicle induction and promote interfollicular epidermal fate in developing mouse skin. Development. 2009; 136:2153-2164. [PubMed: 19474150]

98. Moon RT, Kohn AD, De Ferrari GV, Kaykas A. WNT and beta-catenin signalling: diseases and therapies. Nature reviews Genetics. 2004; 5:691-701.

99. Lowry WE, et al. Defining the impact of beta-catenin/Tcf transactivation on epithelial stem cells. Genes Dev. 2005; 19:1596-1611. [PubMed: 15961525]

100. Choi YS, et al. Distinct functions for Wnt/beta-catenin in hair follicle stem cell proliferation and survival and interfollicular epidermal homeostasis. Cell Stem Cell. 2013; 13:720-733. [PubMed: 24315444] 
101. Lim X, et al. Interfollicular epidermal stem cells self-renew via autocrine Wnt signaling. Science. 2013; 342:1226-1230. [PubMed: 24311688]

102. Wilson SI, et al. The status of Wnt signalling regulates neural and epidermal fates in the chick embryo. Nature. 2001; 411:325-330. [PubMed: 11357137]

103. Andl T, Reddy ST, Gaddapara T, Millar SE. WNT signals are required for the initiation of hair follicle development. Developmental cell. 2002; 2:643-653. [PubMed: 12015971]

104. Huelsken J, Vogel R, Erdmann B, Cotsarelis G, Birchmeier W. beta-Catenin controls hair follicle morphogenesis and stem cell differentiation in the skin. Cell. 2001; 105:533-545. [PubMed: 11371349]

105. Gat U, DasGupta R, Degenstein L, Fuchs E. De Novo hair follicle morphogenesis and hair tumors in mice expressing a truncated beta-catenin in skin. Cell. 1998; 95:605-614. [PubMed: 9845363]

106. van Genderen C, et al. Development of several organs that require inductive epithelialmesenchymal interactions is impaired in LEF-1-deficient mice. Genes Dev. 1994; 8:2691-2703. [PubMed: 7958926]

107. Balciunaite G, et al. Wnt glycoproteins regulate the expression of FoxN1, the gene defective in nude mice. Nat Immunol. 2002; 3:1102-1108. [PubMed: 12379851]

108. Osada M, et al. The Wnt signaling antagonist Kremen1 is required for development of thymic architecture. Clin Dev Immunol. 2006; 13:299-319. [PubMed: 17162372]

109. Pongracz J, Hare K, Harman B, Anderson G, Jenkinson EJ. Thymic epithelial cells provide WNT signals to developing thymocytes. Eur J Immunol. 2003; 33:1949-1956. [PubMed: 12884861]

110. Kuraguchi M, et al. Adenomatous polyposis coli (APC) is required for normal development of skin and thymus. PLoS genetics. 2006; 2:e146. [PubMed: 17002498]

111. Lin S, Wang B, Getsios S. Eph/ephrin signaling in epidermal differentiation and disease. Seminars in cell \& developmental biology. 2012; 23:92-101. [PubMed: 22040910]

112. Cejalvo T, et al. Ephrin-B-dependent thymic epithelial cell-thymocyte interactions are necessary for correct $\mathrm{T}$ cell differentiation and thymus histology organization: relevance for thymic cortex development. J Immunol. 2013; 190:2670-2681. [PubMed: 23408838]

113. Munoz JJ, et al. Thymic alterations in EphA4-deficient mice. J Immunol. 2006; 177:804-813. [PubMed: 16818734]

114. Vergara-Silva A, Schaefer KL, Berg LJ. Compartmentalized Eph receptor and ephrin expression in the thymus. Mech Dev. 2002; 119 (Suppl 1):S225-229. [PubMed: 14516690]

115. Lin S, Gordon K, Kaplan N, Getsios S. Ligand targeting of EphA2 enhances keratinocyte adhesion and differentiation via desmoglein 1. Molecular biology of the cell. 2010; 21:39023914. [PubMed: 20861311]

116. Genander M, Holmberg J, Frisen J. Ephrins negatively regulate cell proliferation in the epidermis and hair follicle. Stem cells. 2010; 28:1196-1205. [PubMed: 20506314]

117. Guo H, et al. Disruption of EphA2 receptor tyrosine kinase leads to increased susceptibility to carcinogenesis in mouse skin. Cancer research. 2006; 66:7050-7058. [PubMed: 16849550]

118. Green KJ, Simpson CL. Desmosomes: new perspectives on a classic. The Journal of investigative dermatology. 2007; 127:2499-2515. [PubMed: 17934502]

119. Sano $S$, et al. Stat3 in thymic epithelial cells is essential for postnatal maintenance of thymic architecture and thymocyte survival. Immunity. 2001; 15:261-273. [PubMed: 11520461]

120. Alfaro D, et al. Alterations in the thymocyte phenotype of EphB-deficient mice largely affect the double negative cell compartment. Immunology. 2008; 125:131-143. [PubMed: 18397270]

121. Pasquale EB. Eph-ephrin promiscuity is now crystal clear. Nature neuroscience. 2004; 7:417418.

122. Tsai PT, Lee RA, Wu H. BMP4 acts upstream of FGF in modulating thymic stroma and regulating thymopoiesis. Blood. 2003; 102:3947-3953. [PubMed: 12920023]

123. Hager-Theodorides AL, et al. Bone morphogenetic protein $2 / 4$ signaling regulates early thymocyte differentiation. J Immunol. 2002; 169:5496-5504. [PubMed: 12421925]

124. Hawley SH, et al. Disruption of BMP signals in embryonic Xenopus ectoderm leads to direct neural induction. Genes Dev. 1995; 9:2923-2935. [PubMed: 7498789] 
125. Nikaido M, Tada M, Takeda H, Kuroiwa A, Ueno N. In vivo analysis using variants of zebrafish BMPR-IA: range of action and involvement of BMP in ectoderm patterning. Development. 1999; 126:181-190. [PubMed: 9834197]

126. Botchkarev VA, et al. Noggin is a mesenchymally derived stimulator of hair-follicle induction. Nature cell biology. 1999; 1:158-164.

127. Jamora C, DasGupta R, Kocieniewski P, Fuchs E. Links between signal transduction, transcription and adhesion in epithelial bud development. Nature. 2003; 422:317-322. [PubMed: 12646922]

128. Kulessa H, Turk G, Hogan BL. Inhibition of Bmp signaling affects growth and differentiation in the anagen hair follicle. The EMBO journal. 2000; 19:6664-6674. [PubMed: 11118201]

129. Bleul CC, Boehm T. BMP signaling is required for normal thymus development. J Immunol. 2005; 175:5213-5221. [PubMed: 16210626]

130. Patel SR, Gordon J, Mahbub F, Blackburn CC, Manley NR. Bmp4 and Noggin expression during early thymus and parathyroid organogenesis. Gene expression patterns: GEP. 2006; 6:794-799. [PubMed: 16517216]

131. Blanpain C, Lowry WE, Pasolli HA, Fuchs E. Canonical notch signaling functions as a commitment switch in the epidermal lineage. Genes Dev. 2006; 20:3022-3035. [PubMed: 17079689]

132. Moriyama M, et al. Multiple roles of Notch signaling in the regulation of epidermal development. Developmental cell. 2008; 14:594-604. [PubMed: 18410734]

133. Rangarajan A, et al. Notch signaling is a direct determinant of keratinocyte growth arrest and entry into differentiation. The EMBO journal. 2001; 20:3427-3436. [PubMed: 11432830]

134. Anderson G, Pongracz J, Parnell S, Jenkinson EJ. Notch ligand-bearing thymic epithelial cells initiate and sustain Notch signaling in thymocytes independently of $\mathrm{T}$ cell receptor signaling. Eur J Immunol. 2001; 31:3349-3354. [PubMed: 11745352]

135. Tadeu AM, Horsley V. Epithelial stem cells in adult skin. Current topics in developmental biology. 2014; 107:109-131. [PubMed: 24439804]

136. Aw D, Taylor-Brown F, Cooper K, Palmer DB. Phenotypical and morphological changes in the thymic microenvironment from ageing mice. Biogerontology. 2009; 10:311-322. [PubMed: 18931936]

137. Driskell I, et al. The histone methyltransferase Setd8 acts in concert with c-Myc and is required to maintain skin. The EMBO journal. 2012; 31:616-629. [PubMed: 22117221]

138. Mejetta $S$, et al. Jarid2 regulates mouse epidermal stem cell activation and differentiation. The EMBO journal. 2011; 30:3635-3646. [PubMed: 21811233]

139. Driskell RR, et al. Distinct fibroblast lineages determine dermal architecture in skin development and repair. Nature. 2013; 504:277-281. [PubMed: 24336287]

Wiley Interdiscip Rev Dev Biol. Author manuscript; available in PMC 2015 November 01. 

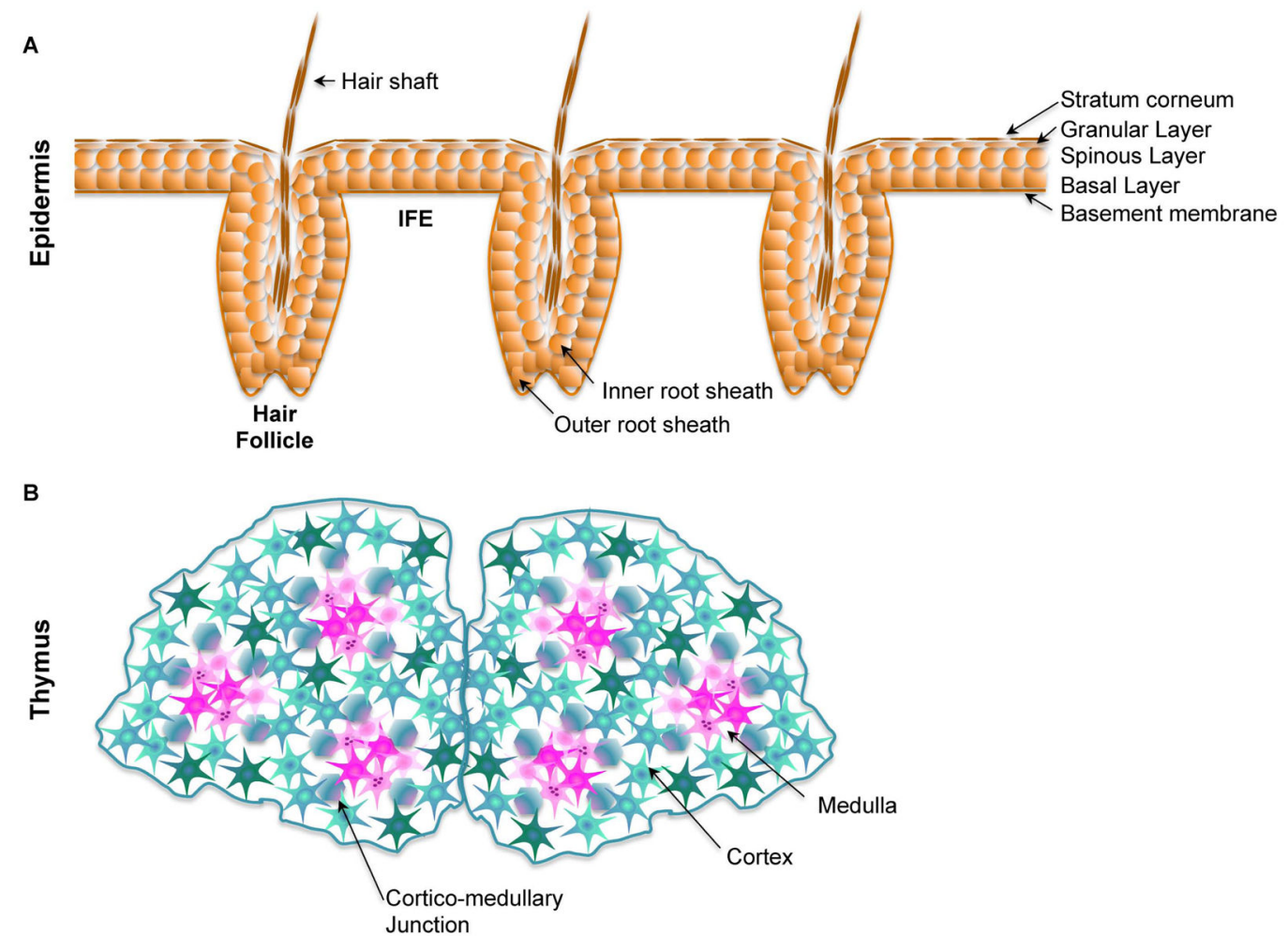

Figure 1. Schematic Representation of the Histology of the Skin and Thymus Epithelium A) The skin epithelium is comprised of the interfollicular epidermis and contains epidermal appendages, such as the hair follicle. Multiple stratified layers of differentiated keratinocytes with different characteristics create an intricate barrier. B) The thymus is a bi-lobed organ that contains two major compartments of epithelial cells, the outer cortex (blue cells) and medulla (pink cells) that form a three-dimensional organ. 


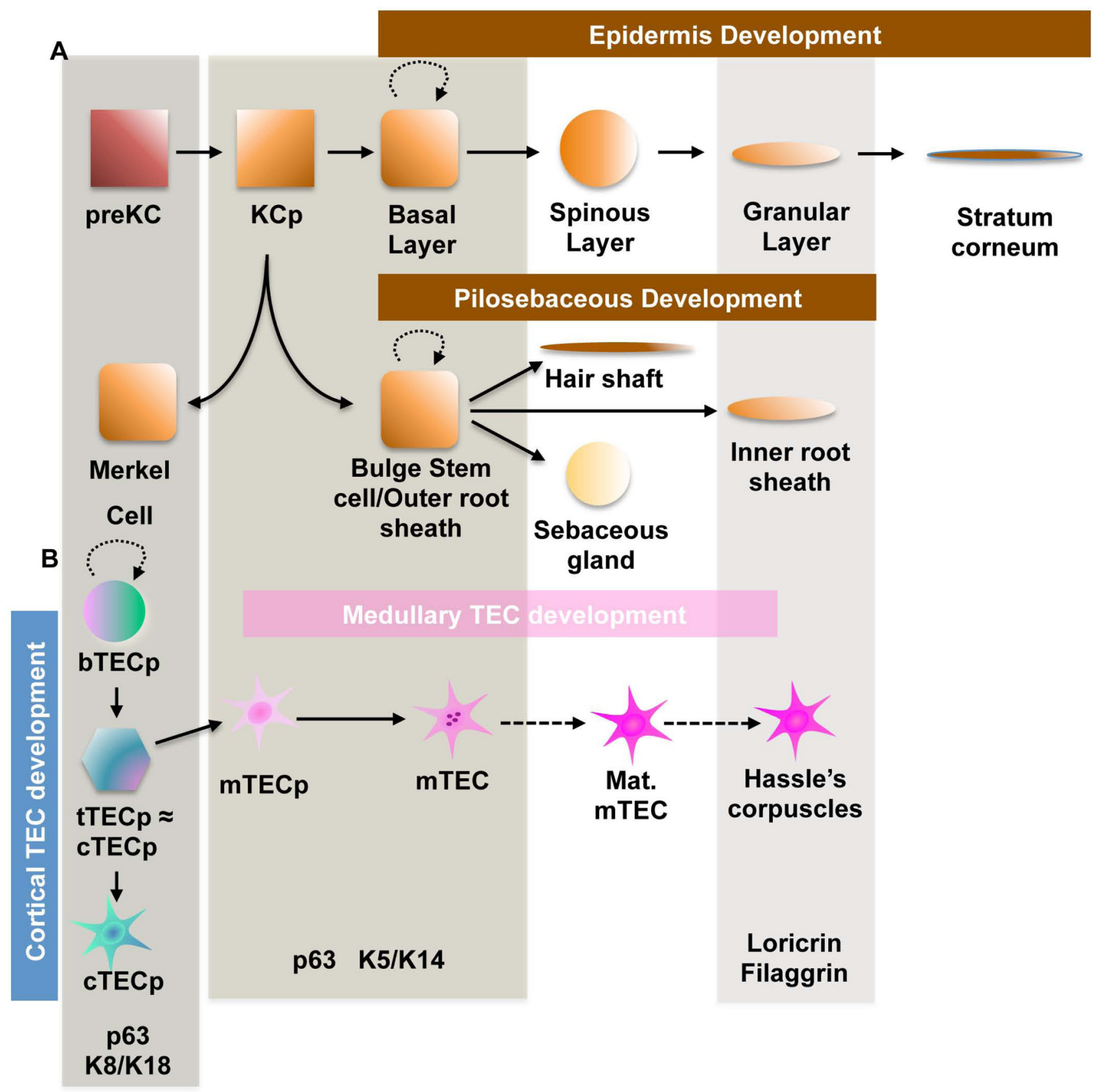

Figure 2. Model Of Skin Epithelium and Thymic Epithelium Development

A) Schematic illustrating the serial progression of epidermal keratinocytes from prekeratinocyte progenitor cells (preKC) to keratinocyte progenitor cells (KCp), which generate epidermal lineages, pilosebaceous progenitors and Merkel cells. B) Schematic illustrating thymic epithelial development. Bipotent thymic epithelial cells (bTECp) generate a progenitor that has greater cortical features (tTECp) that form cortical TEC progenitors (cTECp) and medullary TEC progenitors (mTECp). Both of these progenitors form immature and mature TECs of their lineage. Mature mTECs form Hassle's corpuscles in their final differentiation step. Circular arrows represent self-renewal. Shared markers are illustrated at the bottom. 
A
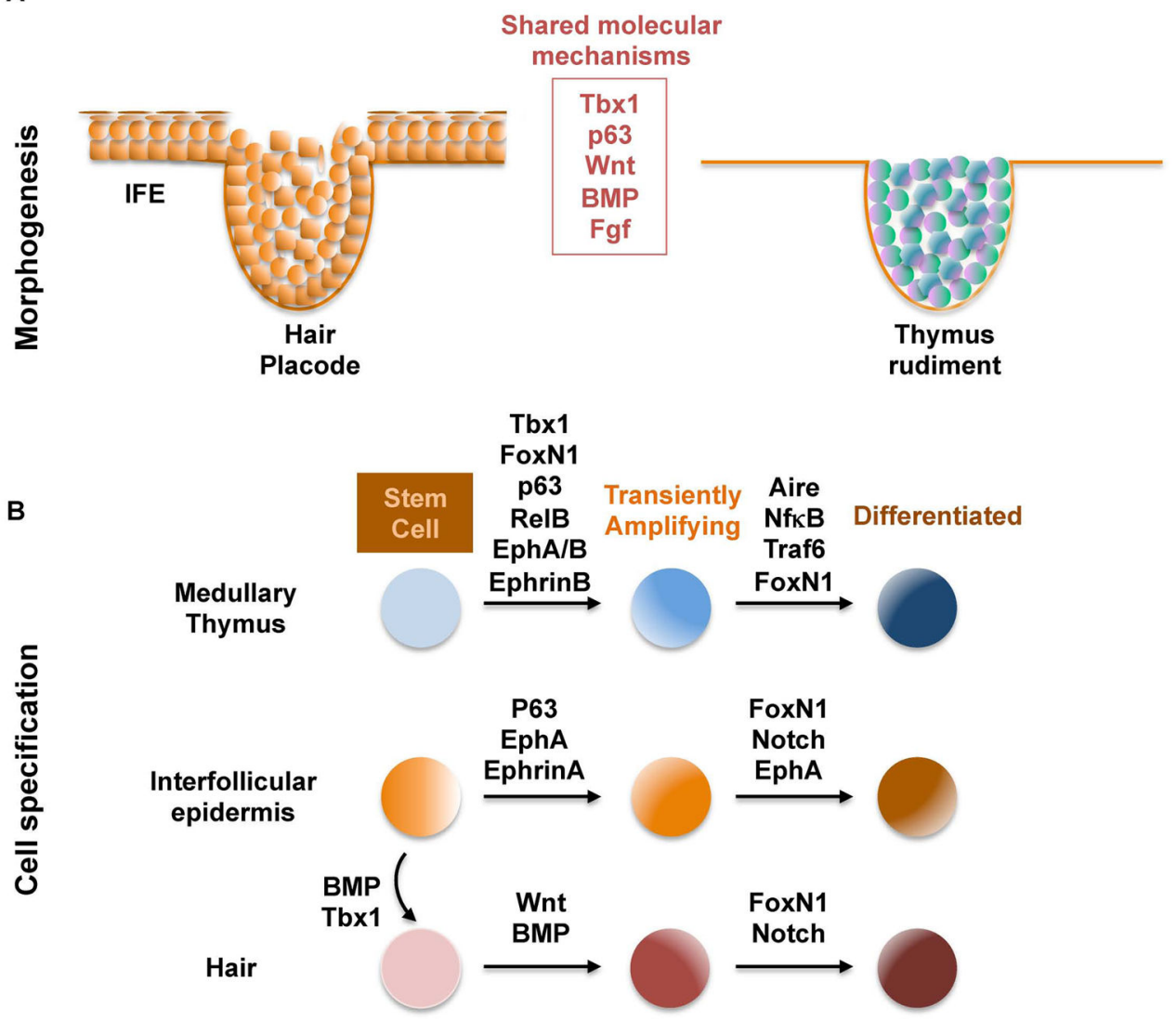

Figure 3. Comparison Of Skin and Thymic Epithelial Molecular Mechanisms

A) Common signaling pathways utilized by both the thymus rudiment and hair placode during morphogenesis are indicated in Red. B) Cell specification utilizes some common signaling pathways as morphogenesis. Signaling pathways important at specific stages are indicated. SC, stem cell. TA, transit amplifying cell. Diff, differentiated cell. 